\title{
Precursor Radiopharmaceutical Solution Dosage Form
}

National Cancer Institute

\section{Source}

National Cancer Institute. Precursor Radiopharmaceutical Solution Dosage Form. NCI

Thesaurus. Code C149881.

Liquid preparation consisting of a solution containing a radionuclide produced for the radio-labelling of another substance prior to administration. 